\title{
11
}

\section{Walking on the village paths: Kanaawoq in Yap and rarahan in Yami}

\author{
Yu-chien Huang ${ }^{1}$
}

\section{Path, pathway, pathing}

The idea of 'paths' or 'pathways' is immensely important to the historical consciousness of people of Southeast Asia, Indonesia and Oceania (Rosaldo 1980; Lutz 1988; Traube 1989; McKinnon 1991, 1995; Tilley 1994; Parmentier 2002). As Tilley noted, paths are understood as 'a way of doing something as method, technique, pattern or strategy'; paths also denote 'fishing techniques, oratorical skills, patterns of exchange and strategies of warfare' in Indonesia and Oceania but fundamentally involve 'establishing and maintaining social linkages and relations' (Tilley 1994: 30) such as the enduring marriage alliance routes (McKinnon 1991, 1995). In different cultural settings, the idea of 'walking on the path' can hold different meanings. For example, walking on the path connotes a sense of improvising and self-decision among the Ilongot in the Philippines (Rosaldo 1980). For the Mambai in Timor-Leste, walking on the path conveys a sense of hierarchical positionality coupled with

\footnotetext{
1 I am deeply grateful to Professor Susan McKinnon for giving me marvellous advice on my first draft, and to Professor James Fox for his warm encouragement and insightful comments.
} 
imagery of a spatiotemporal journey that began at the time of originusually coming from the mountain and resulting in the present position (Traube 1989). In Yap, walking on the path denotes conformity to the past and deference to the land (Throop 2010: 132-34).

Referencing Parmentier's study of Belau metaphors of hierarchy, Fox emphasises the significance across Austronesia of the idea of a path in local understandings and experiences of hierarchy, and its connection to the botanical imagery of trunk and tip, origin and issue and centre and periphery: ${ }^{2}$

A particularly striking example is evident in narratives of Belau as described by Richard Parmentier in The Sacred Remains [1987]. His description of Belau's mythology links the two common Austronesian metaphors, that of the 'path' with its 'origin' to the botanic image of the growing and spreading 'tree' that extends from its base. (Fox 2006: 9)

Using Peirce's theory of signs, Parmentier's series of works begins with a concern with historical process in Balau and how history has been systematically registered in the diagrammatic representations to the Belauans themselves. Those representations include linear paths, balanced sides, quadripartition and graded series and undergo a four-part analysis: lexical labels, schematic arrangements, prototypical embodiments (physical prototypes) and semantic fields (Parmentier 1985, 1987), as Figure 11.1 shows. He argues that the 'quadripartite ideology' ramifies in every level: four powerful villages, four chief houses within a large village, four ranking titles in a council and four satellite houses surrounding a principal house. ${ }^{3}$

2 Fox (2006) further argues for the comparative study of Austronesian 'pathways' to investigate the representation of relations and their transformations in the Austronesian world.

3 Notably, the quadripartition is marked by the diagram of the four stone corner posts with a mythical, maternal and foreign origin: they were believed to be transformed from the four children born to a goddess who landed on Belau after the flood (Parmentier 1987: 4). 


\begin{tabular}{|c|c|c|c|c|}
\hline Lexical label & English gloss & Schema & Physical prototype & Semantic field \\
\hline rael & path & $\rightarrow \square$ & $\begin{array}{l}\text { forest trail } \\
\text { ocean path }\end{array}$ & $\begin{array}{l}\text { positive identity of elements } \\
\text { sequential precedence } \\
\text { obligation of repetition }\end{array}$ \\
\hline bitang & side & a & $\begin{array}{l}\text { river banks } \\
\text { body symmetry }\end{array}$ & $\begin{array}{l}\text { identical opposed terms } \\
\text { balanced reciprocity } \\
\text { mutual implication } \\
\text { full complement on both sides }\end{array}$ \\
\hline saus & cornerpost & D & $\begin{array}{l}\text { supporting stones or } \\
\text { pillars of building }\end{array}$ & $\begin{array}{l}\text { underlying support } \\
\text { coordination } \\
\text { differential function }\end{array}$ \\
\hline klou/kekere & $\begin{array}{l}\text { larger/ } \\
\text { smaller }\end{array}$ & ם & $\begin{array}{l}\text { relative physical size } \\
\text { relative marurity }\end{array}$ & dominance/subordination \\
\hline
\end{tabular}

\section{Figure 11.1 Diagrammatic icons of Beluan social relations}

Source: Parmentier (1987: 110).

Among the four semantic fields, the first, 'path', deserves our attention here. As a semantic field, 'path' includes three features that 'derive from reflection on journeys or migrations along trails' (Parmentier 1987: 109). Those features are 'points' such as sacred stones, trees, valuables, placenames and titles; they are symbolic markers for those locations where 'a god or ancestor stopped on the journey which began the path' (Parmentier 1987: 109). The second feature, sequential precedence, derives from the link connected via those points. The sense of sequential precedence consists of an origin, which implies 'seniority in ceremonial precedence' (Parmentier 1987: 109). The third feature is a linear order, which implies 'the possibility for repeated action with prescribed confines, whether it be retracing a footpath through the forest, pursuing well-attested methods of fishing, or following established social linkages' (Parmentier 1987: 109). Those 'paths' serve as 'sign types' in semiotics or:

general regularities that impose their template or pattern on 'sign tokens,' so that these individual occurrences are meaningfully categorizable as instances or 'replicas' (to use Peirce's terms) of the general rule. (Parmentier 1987: 109-11)

Parmentier's work foregrounds the significance of the landscape coded with modalities of social relations - for example, the semantic field 'path', consisting of points (ancestors' historical deeds), sequential precedence (linkages) and linear order (repetition). Along with three other semantic fields-balanced sides, corner posts and graded series_-'path' signifies historical consciousness. Parmentier's work also represents the profound 
semiotics of landscape and may coincide with the historicity of Beluan cosmology (Parmentier 1985, 1987). However, his semantics has left very little room for interpersonal interactions and everyday life richness; how those modalities are inscribed into persons, other than through linguistic forms, remains unexplored (Parmentier 1984, 1985, 2002). In this regard, Throop's phenomenological approach demonstrates how 'path is the teacher' and a person's movement over land gradually encodes social values—such as being mindful, vigilant and respectful—into one's body (Throop 2010: 132-34). Tilley's and Harrison's work has also shown how humans, as perceiving and experiencing subjects, read and encode the 'grammar of the space' in their bodily movement across the land (Tilley 1994; Harrison 2004).

As there is vast cultural diversity within the Austronesian world, so, too, is there diversity in the meaning of 'paths' and 'walking on the path'. Here, I use the spectrum of egalitarian-hierarchical to show the contrast. For the egalitarian peoples, such as the Ilongot (Bukalot) living in the highlands of the Philippines, walking on the mountain paths denotes improvisation and self-decision. For them, social order is repeatedly improvising, just as a group of people walking on a path sometimes gather and sometimes disperse. On the contrary, for a hierarchical society, the meaning of improvising is much less emphasised. 'Path' is a metaphor of hierarchy and usually carries some common characteristics, such as the trunk and tip of a tree, the origin and branch, the centre and periphery or the spatial-temporal journey stretching from the ancestors' origin place to the present (Traube 1989). Therefore, 'walking on the path(s)' entails dissimilar meanings in a hierarchical society than in an egalitarian society.

\section{Scope of comparison}

This chapter will focus on the diverse configuration of village paths: kanaawoq in Yap and rarahan in Yami. A kanaawoq in Yap is clean, wide, smooth and weed-free. People walking on a kanaawoq have to conform to certain decorum: demonstrating respect by walking slowly and mindfully and talking softly. Meanwhile, the rarahan in a Yami village is narrow, zigzagging and irregularly sandwiched between individual house compounds, and the villagers' individual walking routes on rarahan frequently change for various reasons - such as disputes and feuds, mortuary rituals or when carrying excessive loads of fish. Therefore, the 'path' for the Yami does not denote normative behavioural protocol; it refers to innovation. 
Having conducted research on both islands, I believe the difference between village paths in Yap and Yami is not as arbitrary as it appears. Unrelated historically, they seem to occupy two ends of a spectrum between hierarchy and equality within the scope of comparative Austronesian studies. By examining the idea of village paths in two cultures, I hope to discuss the indexicality of 'path' in regard to social order in this comparison, as well as investigate the significance of 'pathing'.

I should note here that among the various meanings and metaphors of 'path', I focus only on the concept of 'village path'. I will discuss how Yapese accommodate their behaviour to the existing village paths, as well as how Yami improvise pathing in the village. I have not included other semantic fields, such as marriage pathways, paths in the wilderness, forests, gardens or paddy fields or paths as methods and techniques. It would be ideal if in the near future I am able to investigate the indexicality/iconicity of the polysemic concept of 'path' and its various forms in Yap and Yami. It might reveal something distinctive in the Austronesian cultures- that is, how humans' signifying practice constantly encodes and transforms cultural indexes that oscillate between hierarchy/equality, collective/ individual and normative/improvising.

\section{Yap (path as the teacher)}

Yap, called Wa'ab (Uav) by its inhabitants (Müller 1942: 2), is a high volcanic island in the Western Caroline Islands of Micronesia. As an Austronesian language, Yapese probably belongs to the Western MalayoPolynesian or 'a highly conservative' Oceanic language (Ballantyne 2005; Throop 2005: 99-101, 2010: 18). ${ }^{4}$ It has long been known in anthropology for the difficulty of categorising it in any kinship theory classification (Goody 1961; Schneider 1962, 1984) and for its strong hierarchy in this region of the Pacific (Hezel 1983; Bashkow 1991; Throop 2010: 31). In this regard, Throop has carefully argued that the Yapese hesitation to cultural change is mainly attributed to their cultural valuation of careful deliberation, thoughtful action and a morality that emphasises mutuality of being-how the individual internalises community goals as their own

4 Given the extensive borrowing from different language groups, Oceanic and non-Oceanic (Blust 1988: 58-59; Ballantyne 2005: 22; also see Tryon 1995: 28), Yapese is not easily classified within the Austronesian language family. 
desires (Throop 2010: 31; Sahlins 2011a, 2011b). In this chapter, I focus on walking on the village paths, which is a demonstration of internalising community values.

Yapese have several terms referring to paths or roads, such as woqlwol' ('road', 'way'), rogon ('way', 'road', 'method') and kanaawoq ('way', 'road', 'path', 'method'). Here, I emphasise kanaawoq. It is a special kind of road that existed prior to the colonial period and was usually paved with stones or coral. It connects tabinaw ('house estates') within and across villages. ${ }^{5}$ Yapese value stone paths greatly, and they are a focus of historical preservation (Krause 2016: Chs 7, 8). There are many regulations for walking on this kind of road.

Kanaawoq refers to 'paths, methods'. The significance can be compared with Paluan rael: 'a way of doing something' (Parmentier 1987: 109). Throop points out that 'path is the teacher' - that is, movement across the land has gradually encoded social values, such as being mindful and vigilant (2010: 132-34), into the body. The design of the path is itself normative: individuals walking on the path have to be careful and concentrate on the tasks at hand. For example, walking on a stone path covered with moss, one has to be mindful of one's steps and cannot look around at others' properties, such as gardens, trees and taro-paths. The technique of building the stone path ensures one needs to pay full attention to one's steps: Daamu changar, mu saap ngaa buut ('Don't you look around, you look to the ground') (Throop 2005: 295). 'Path as the teacher' keeps reminding those who walk on the pathway to be humble, respectful and mindful of the tasks at hand. Walking on the stone path can be considered as walking meditation (Throop 2010: 133-34):

In many ways, the path (kanaawoq) was characterized as a material reflection of the valuation of reflective action ... The very ways in which the rocks are placed on the path serve as a message from the piiluung ${ }^{6}$ and community to the people walking along it. The path's message is that travelers should always demonstrate respect

5 I was told there are two kinds of kanaawoq: kanaawoq ni gaa ('big roads' or 'main roads'), connecting villages (sometimes across municipalities), and kanaawoq ni ichig ('smaller roads'), connecting villages within a municipality, among tabinaws within a village or between two big roads. Large numbers of kanaawoq are paved with stones or coral. Unpaved kanaawoq were made from material removed during the Japanese colonial period from roads for motor vehicles.

6 Piiluung is usually translated as 'chief'. Luung or lunguun means 'voice'; piiluung literally means 'many voices'. Thus, piiluung is understood as the collective voice of individuals in the village (Throop 2010: 36-37). 
(liyoer) when traveling in the village. Practically speaking, walking along a Yapese stone path is no simple matter. The rocks are very smooth, often covered with moss, and are, as a result, quite slippery. This is especially so during or after a rainfall. Without careful attention to where you are placing your feet, it is quite easy to fall. When walking on a path it is often necessary to look down to see where you are stepping. In the process, individuals are restricted by the design of the path itself to walk deliberately and slowly, with their heads down. (Throop 2010: 132-33)

In Yap, walking on the village paths means one has to obey the village rules, unlike the Ilongot's improvised walking. Rather, Yapese emphasise following predecessors' rules and respecting the land (Throop 2010: 132-34). Hence, people's lived experience in the landscape is not highly creative and marks the differentiation between generations; the landscape constrains subjects' movements. If we ask how Yapese walk in the village, almost everyone's answer is similar: walk in single file and not side-byside; men walk in front and women behind; one has to carry a twig in one's hand or under one's armpit. Women usually carry a long basket and men carry a man's basket. One does not look around, but looks at the road, slowly and deliberately, which symbolises respect for the land (binaw). Visitors in particular have to obey the rules.

To paraphrase the archaeologist Christopher Tilley (1994: 29), if the 'grammatical system' is inscribed in the cultural space, what is the grammar of space inscribed in Yap? The answer is clear: hierarchy. In Yap, everything — space, crops, land, garments, status - is hierarchical. For Yapese, there are no two things or two persons on the same level; there is always a status difference between one and another person. Anthropologists have used the Dumontian model of Indian hierarchy, distinguishing the Yapese structure of hierarchy between tabugul ('pure') and ta'ay ('impure'). To quote Labby:

Like the living area space within the estate, the village was divided into areas that were tabugul and taay. The estates of high status and the taro patches of the top yogum were said to usually be near the center of the village. These areas were generally prohibited to young, fertile women and people of the lower village ranks. The top tabugul taro patches were definitely off limits to such people, and only men or women who had ceased to menstruate could work them and collect food from them. Lower estates and taro patches were more and more toward the outskirts of the village, near the 
paths for the rugoth women and lower villages. The taro patches would furthermore be arranged so that the water flowing through them went into the higher ones first so that it would not pick up contamination. (1976: 83)

Labby has also pointed out that Yapese are cautious to not step into others' territories. Young women would not go to the tabugul taro patches; only those of higher status could enter. If a woman accidentally goes into those taro patches, the taro will rot and she will become infertile. If the woman is still very young (very ta'ay), she may even die. On the contrary, if 'men of the top yogum' ('eating grades') consume food from lower-grade taro patches, they will 'get sores on their throats and become unable to eat ... blood would run out of their mouths, and ... they could even die' (Labby 1976: 83-84).

Not only do Yapese respect stone paths, as Throop has noted, but also the stone paths are important items of cultural heritage preservation (Krause 2016) and, as such, Yapese would emphasise that, in contrast to other Micronesian islands, Yapese stone paths are relatively unchanging. If a tree grows on the road, other Micronesian islands may let the tree grow and walk around it, but Yapese will almost immediately remove any obstacle on the road to ensure it remains intact and unchanging (Throop 2010: 132). In the village where I stayed, the main path-especially the section lined with stone money - was weeded manually every other month, and every household had to contribute labour (or money) to maintain the road. The weeds had to be pulled by hand, rather than using the weeding machine, to demonstrate respect to the spirit inhabiting the road. The principle that 'the road has to be kept clean' is deeply rooted in Yapese cultural values and practices. In other words, the 'path', as a teacher, remains relatively unchanging, and is taken care of by relatives, ancestors and the persons whom it connects. The paths have to be maintained month by month, generation by generation, carefully and mindfully. Similarly, those walking on the path have to obey the corresponding rules, encoding the grammar of the space into their bodily behaviour through obedience and mindfulness. ${ }^{7}$

7 Yapese of different status, gender and age have to walk on different paths. Some are the respected paths, requiring more protocols to walk on them. Young female and low-ranking people should walk on different paths. 
To a certain extent, for Yapese, a 'path' is created by people walking on it, but persons are also shaped and made by the 'path', which is loaded with historical and cultural significance. ${ }^{8}$

\section{Thaaq}

Another Yapese word, thaaq (closely related to paths: kanaawoq) also captures the rich meanings of 'path' in Yap society. Thaaq refers to strings, threads, connections and relationships. ' It signifies 'a long line of communication that ties together the various geographical and political units of Yap' (Lingenfelter 1975: 131). ${ }^{10}$ Therefore, thaaq implies authenticated conduits of communication. Its authenticity is clearly stated by Lingenfelter:

[A]ny legitimate request or message must follow the channels of communication, or thaaq. This is a very serious matter to the Yapese, and if word is passed improperly, regardless of its importance, it may be disregarded. (1975: 131)

Thaaq legitimates almost all perceptible traditional authorities in Yap, from piiluung ('chiefs') at all levels to the three paramount seats of power, Dalip pi Nguchol ('The Three Paramount Chiefs' or 'three supporting stones of a cooking pot')— the three highest tabinaw ('house estates'). Similar to 'eating grades' (yogum), which are no longer practised, people may appear oblivious to certain thaaq these days. Nevertheless, thaaq is still a highly sensitive topic in contemporary Yap. ${ }^{11}$ I was forewarned several times that thaaq is not supposed to be discussed in public, especially not in front of foreigners. ${ }^{12}$

8 The respect Yapese show to kanaawoq relates to Yapese sentiment and respect towards the land. For the Yapese, binaw ('land') is where identity is tied and where social personhood is marked and cemented by the labour of generations of ancestors. When a Yapese is making a public speech, the opening is always sirow ko piiluung; sirow ko binaw ('Excuse me, chiefs; excuse me, the land').

9 A 66-year-old Yapese man described thaaq as powerlines: 'Because of power lines, the electricity is able to be carried through.'

10 Thaaq can also refer to a type of pandanus (screw palm).

11 The only case I heard where thaaq was openly discussed was at men's meetings among the elders of certain tabinaw in high-ranking villages, such as Gachpar.

12 The knowledge of political connections is categorised as machib ('knowledge within the family' or 'family teachings') and is not easily revealed to outsiders. I admire those predecessors who were able to detail thaaq, such as Lingenfelter (1975) and Ushijima (1987). In my experience, thaaq is a sensitive issue. People advised me not to investigate thaaq too much to protect myself. I consider the ethnographical accounts on thaaq as embodiments of mutual trust between the researchers and the Yapese. 
Thaaq vividly epitomises the Yapese concept of relations and power. A village community is never a holistic, self-contained social entity. It is penetrated by and constructed through a web of connections. I was reminded from the time of my first visit that not all tabinaw ('house estates') in a village share the same rank or status, and there may be several piiluung in a village community, each in charge of different spheres of social life.

Ushijima has detailed an example in Gilfith village, Fanif Municipality, to explain how luungun ('voice') has to be passed according to appropriate thaaq (1987). Briefly, it means only a certain tabinaw in the village has the thaaq to transmit luungun. For example, Gilfith and nearby Rang villages belong to different political alliances (baan: 'sides'). If the piiluung of Gilfith village wants to convey a message to Rang village, instead of communicating directly, the message has to be passed through a certain tabinaw - the 'ears and eyes' of another side. Similarly, if the head tabinaw in Rang village has a message for the chief in Gilfith village, it has to be passed through the same tabinaw (Ushijima 1987: 193). Nevertheless, for the villages belonging to the same side, the chiefly tabinaws have direct connections with one another; messages do not need to be mediated by the 'ears and eyes' of the other side.

This system seems confusing to outsiders at first glance. It may be easier to comprehend if we imagine it as different telephone companies or computer operating systems in modern life. ${ }^{13}$ Ushijima once described the complexity of thaaq as follows:

The particular tha' [thaaq] employed depends on the nature of the message to be transmitted. One tha' is used for the supply of materials and labour for projects such as [the] building of meeting houses. Another tha' is used to secure military assistance and communicate battle plans in times of war. Still another tha' is used for invitations to ritual exchange. And, apart from these, there is the tha' ko wolbuw. Wolbuw is the annual ritual exchange of food which is performed at a predetermined time of year. Different

13 Nonetheless, the concepts similar to thaaq are not unique in Yap. In a non-Austronesian case, in the Arapesh-speaking region (but not restricted to it) of New Guinea, the idea of pathways or roads (yah [singular], yeh/yegwih [plural]) has become a significant local framework of identity since wartime, persisting even after pacification. Roads served as channels for village units' warfare alliances and as safe passages when intervillage warfare was intense, and they continued to be important in local political manoeuvring when European officials were present in the milieu (Dobrin and Bashkow 2006). 
kinds of food, for example, are given as tribute, according to past precedents or in return for assistance received in the past. (1987: 194-95)

I have heard similar descriptions in the field, rendered as 'obligations and privileges', in a simplified version:

One family makes ropes for us; another family replaces the roof for us-now no longer needed because we use tin roofs instead of coconut or napa leaves. But we also provide harvest for other families. So, we work for others while others also work for us. (Male, 60 years old)

In 2014, a large-scale exchange ceremony-mitmit ('stuck stuck' or 'stuck again')—was reactivated in Ngolog, Rull. It was a very rare event since mitmit had not been held for several decades in Yap. In mitmit, thaaq is publicly manifested, demonstrated and reconfirmed. Even 'sending word out'-announcing the completion of the men's house in the village, which was an event worthy of mitmit celebration-had to follow strict protocols with respect to relative traditional political positions. Krause noted:

In Yap's traditional sociopolitical system, official communications between villages must follow strict protocols that have to do with village rankings and relative positions within the bulce and ulun political affiliations. As I was told, there are also specific estates that have the roles of messengers for these communications and it is only the specific representatives from those estates who should be carrying the message. And so when word was officially sent out from Ngolog, all of these messengers were called upon to do their duty in notifying the villages. I had learned that this extremely complex network of communications had not been activated in quite some time. In conversations with friends and colleagues after work, much of the discussion around this time was about who was supposed to contact who $[\mathrm{m}]$, and the orders in which the word was supposed to travel as it made its way through all the villages. (2016: 314; emphasis added)

In one of his dissertation chapters, Krause vividly described people's close attention to this 'extremely complex network of communications'namely, thaaq, which had not been ritually demonstrated for a long time. During the time of my fieldwork (2012-13), anxiety resulting from the confusion of the legitimate thaaq was keenly felt. If the messages were not transmitted through the proper channels, the validity would soon be challenged and even nullified. 
Thaaq signified Yapese traditional politics, which decided the relative ranking of tabinaw ('house estates'), which tabinaw is related to which, which would pay respect to which and which should run errands or do service for which. Those thaaq rankings are the 'chart' of hierarchy, and Yapese interact with one another according to their respective rankings. It is true that since intervillage warfare was prohibited under the German regime, the dynamism of village ranking has diminished. However, thaaq continues to exist and is mobilised whenever necessary.

Thaaq is not unique to Yap. $\mathrm{Va}$ in Samoa shares the same idea of 'routes'. Pathways or connections suggest a profile or network: a village is a knot of various connections on different scales. For Yap, the symbolism of thaaq signifies a certain aspect of sociality: the political alliance. In precolonial times, it meant relative safety, trust, obligations and formal and informal exchanges between the knots on the thaaq. For Yapese, administrative territorial boundaries ('municipalities') are designed for governing, but not for the sociality of the locals. As a Yapese man once told me: 'In the past, we had connections rather than boundaries. ${ }^{14}$

The attitude of seeing the 'path' as the teacher, expecting one to be vigilant and respectful while walking on the path, has demonstrated the Yapese valuation of being humble and respectful — to the environment and to other people. The norms of walking on the path are similar to those of Yapese dancing: mastery of one's own bodily movements is an achievement in selfrestraint and self-governance (Throop 2009). Yet the 'lesson' of walking is somehow different. Yapese showing respect to the land, the village and community structures (such as the stone paths) is in fact showing respect to their predecessors' investment of labour; numerous generations have worked on the land where contemporary descendants are living and carrying out daily activities. In fact, the labour investment of previous generations has transformed the environment from unclean, underdeveloped and polluting wilderness to an ordered, clean and inhabitable dwelling space-that is, from taay to tabugul (Egan 1998: 135). The land in Yap, as well as the historical stone structures, actually epitomise various degrees of labour investment in the past; land embodies and cements hierarchy. ${ }^{15}$

14 Roy Wagner's well-known paper 'Are there social groups in the New Guinea Highlands?' (1974) is a continuation of David Schneider's 1965 discussion. The data are based on the above-mentioned 'connections, paths', but he has gone far beyond that and challenged the presumption of the 'unit' or 'group' prevalent in anthropological theory at that time.

15 Unlike caste in South Asia, hierarchy in Yap was not immobile; individuals, houses and villages could alter their ranking through warfare or other historical deeds. Since pacification during the German colonial era, village ranking has become fixed. 
In the next section, I will discuss the Yami people in Lanyu (Orchid Island). As an egalitarian society, their concept of 'path(s)' displays a significant contrast with that of the Yapese-in landscaping, in people's movements and the associated etiquettes as well as in the valuations of village paths.

\section{Path(s)/passage(s)/pathing in Yami}

The people living on Orchid Island (previously known as Botel Tobago) ${ }^{16}$ are named the Yami ('we'), but they call themselves Tao ('person[s]'). The Yami language belongs to the Western Malayo-Polynesian subgroup, as does that of the indigenous people of the Batanes archipelago in the Philippines. ${ }^{17}$ In what is characterised as an egalitarian society, the concept of Yami path(s), as for the Ilongot, suggests individual improvisation. Therefore, I use 'pathing' to describe people's movement on the village paths, which constantly varies. To comprehend the Yami's 'individual improvising', I will explain the Yami concept of 'path(s)'.

Unlike Yapese, who have a wide range of words referring to paths and connections, the Yami do not have a rich vocabulary for 'path(s)'. In the Yami language, there is no distinction between 'road' and 'path'. When we ask a Yami about the word referring to paths, roads or passages, rarahan comes as the first and most prevalent answer. Rarahan stems from rahan ('footprints', 'climbing') and refers to paths, roads and trails on which people walk. The cement highway circuiting the island is called nanad ('round-island highway'). ${ }^{18}$ In daily life, rarahan is the most common word for physical paths/roads/pathways.

One defining feature of the village path(s) is their publicness: village paths do not belong to any specific persons or individual households, and every villager can walk on them. Being open to everyone has rendered the village path(s) the very few public spaces in a Yami village. In fact, while walking in a Yami village, the first impression one might have is its lack

16 Orchid Island was named Koto-sho (Redhead Island) in Japanese and Lanyu (Orchid Island) in Chinese. The Yami call it Bonsho no Tao (Island of People).

17 It is believed the Yami migrated to the island from the Batanes archipelago.

18 Another word, onong, means 'do deal with, forever, paths', relating to onot ('stalk, follow'). But onong rarely refers to physical pathways or roads; rather, it usually relates to 'walk past', 'forever' or 'decide by oneself' (Rau et al. 2012: 169-70). 
of static public space. ${ }^{19}$ The nanad ('round-island highway'), which ran through the margin of the village communities, is indeed a public space; however, the nanad was built by the government, does not belong to anyone and no-one really cares about maintaining its cleanliness. Rarahan in the village can be categorised as public and must not be obstructed. Contrary to the village paths in Yap, which are flat, wide and laced with stone money (rai), the Yami village rarahan around traditional house compounds are zigzagging and rugged like small pathways in a paddy field. Because the sizes of traditional house compounds vary, the passages between and around them zigzag accordingly. ${ }^{20}$

Not only do the passages zigzag and demand that people meander, but also the Yami's walking on the path varies from time to time. For example, when a person dies, people avoid walking around the deceased's household. When one catches a lot of fish (especially flying fish), one should not pass through other people's front yards (inaorod). When one is feeding the pigs or carrying crops from the field, one should avoid others' front yards as well. When people are distributing taro and pork from their front yard to reciprocate others' labour contribution (such as in house building), unrelated persons will shun these passages lest they be seen as showing the intention of taking a share. When there is an obstruction on a passage or pathway, or a need to avoid disharmonious relations, the Yami make a detour. Each time-when a burial occurs, when carrying food, when there is an obstacle on the passage- the Yami will find an alternative way to reach their destination, rendering every decision an opportunity (de Certeau 1984: xix). Since the Yami houses are densely concentrated, such events occur very often, and individuals have to choose a suitable itinerary swiftly, resulting in constantly alternating movements within the village. I call the Yami tactical movement 'pathing'-referring to the improvised actions of an experiencing subject to create one's own path.

People pathing denotes this improvisational element. It occurs in the landscape of the paths - the narrow, zigzagging physical space that varies according to the sizes of the nearby houses. To comprehend why the village paths are zigzagged instead of straight, we need to see the Yami

19 For the Yami, the spaces that might be considered 'public', such as the elementary school, churches or the playgrounds built by the government, have come later.

20 Even in the cement house areas, where house owners extend their roofs or pavilions unevenly, the paths have to zigzag around them, and a walker must yield to walk around those blocked spaces. 
house structure, which entails a lack of public space in the Yami village: the house space grows, therefore, the 'public' spaces become jagged around them. ${ }^{21}$

\section{Yami house compounds and their passages}

It is known that the Yami house (and house compound) represents the developmental process of a married couple (Chen 1995: 164). From the time a couple is married and have their first child, they change names (teknonymy), set to work to expand the house and build canoes and hold inauguration ceremonies for achievements in the life course. ${ }^{22}$ Therefore, the growth of a vahay ('main house') can be thought of as a diachronic objectification of a couple's life cycle (Chiang 1986; Chen 1995). Here, I will focus on the spatial plan of the Yami house compound. We can see that Yami cement houses grow as well, gnawing at the passages between the houses, and the Yami improvise their pathing along these passages.

A complete traditional Yami house is a compound, including three building structures: a main house (vahay), a workhouse (makarang) and a pavilion (takagal). ${ }^{23} \mathrm{~A}$ front yard (inaorod), also called an 'extended harbour' (Fang 1984: 81; Kwan 1989: 158), ${ }^{24}$ is part of the house compound (see Figure 11.2), and is surrounded by those three structures. In the household compound, sociability is proportional to the height of

21 Indeed, whether there is a 'public space' and how such a space is defined would be an interesting point to contrast in hierarchical and egalitarian societies. In my observation, public space is clearly demarcated in hierarchical societies but is fluid and often blurred with private space in egalitarian societies. In an egalitarian society, the places where people gather also shift-depending on relations with leaders or ritual hosts.

22 Getting married is the initial stage of becoming a social person because each significant social action is conducted by a couple, while unmarried people are treated as immature children.

23 The main house is located halfway below ground. The Yami cook, dwell (especially in winter), hold inauguration ceremonies and store inherited treasures here. The workhouse's floor is at ground level. The Yami manufacture artefacts and welcome guests in the workhouse, and also sleep there in summer. The pavilion (takagal), built about 60-90 centimetres above the ground, is a place for daily socialising, work and rest.

24 I learned this metaphor - 'the extended harbour' - from Fang's Masters thesis (1984: 81), which has been quoted ever since (see Kwan 1989: 158; Tsai 1997: 41; Huang 2005: 116). But Fang did not document the indigenous term. I have asked several Yami people (who have a decent knowledge of local expressions), but they did not know this expression. The only way to find the indigenous term is to verify it with elders on the island. The closest analogy drawn between the front yard and the sea can be found in Liu's documentation of a ritual lyric from a large canoe inauguration ceremony, in which one line states: 'Comparing your front yard to the sea, the canoes never row away from your front yard' (Liu 1982: 193). The genre of this song was called anohod - a genre frequently used by the Yami in both ordinary and ceremonial events. Anohod lyrics were largely improvised. By contrast, the genre raod is only used in ceremonial song-exchange settings and the lyrics are transmitted from the past, and rarely improvised (Chien 2011). 
the structure, while privacy is in reverse to its height (Chen 1995: 146). Figure 11.3, the profile of a Yami house, illustrates the differences in sociability and privacy among different structures in the house compound.

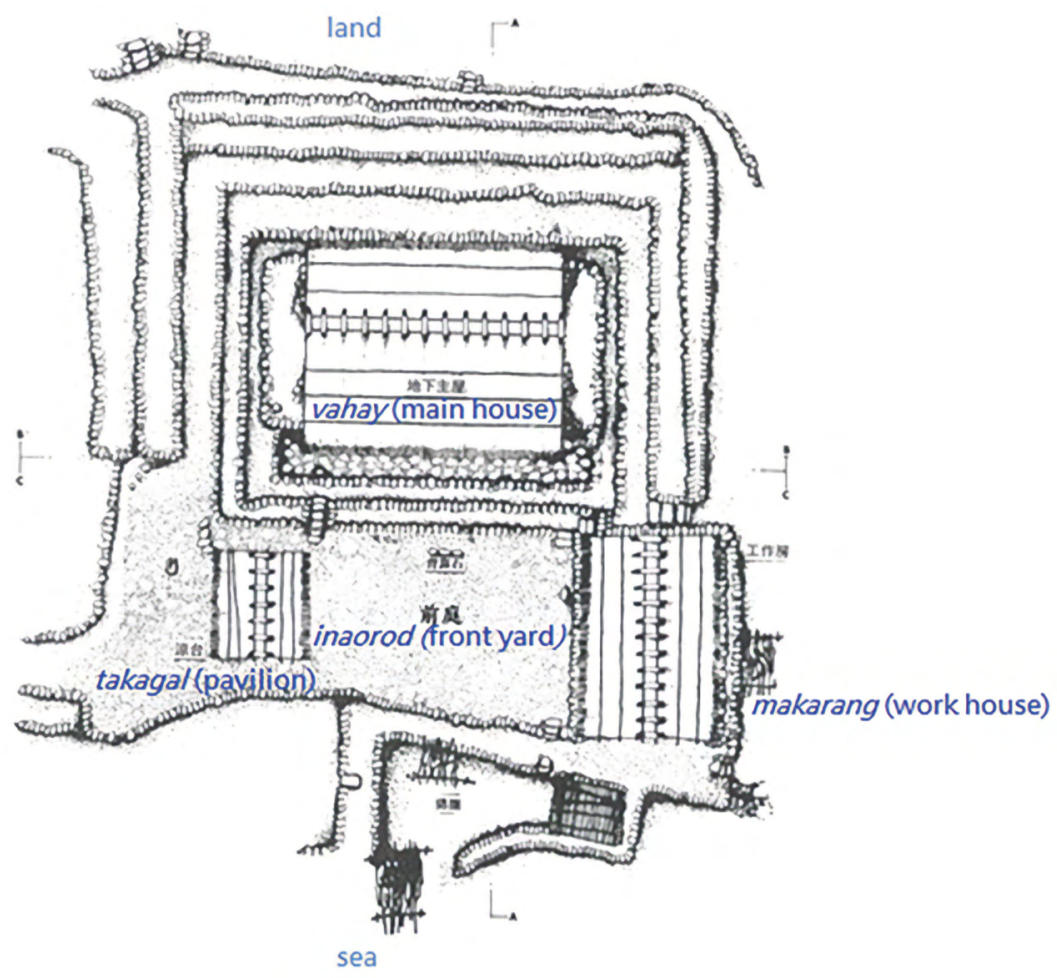

Figure 11.2 The plan of a traditional Yami house

Source: Urban Planning Studio, Department of Civil Engineering, National Taiwan University (1984: 89).

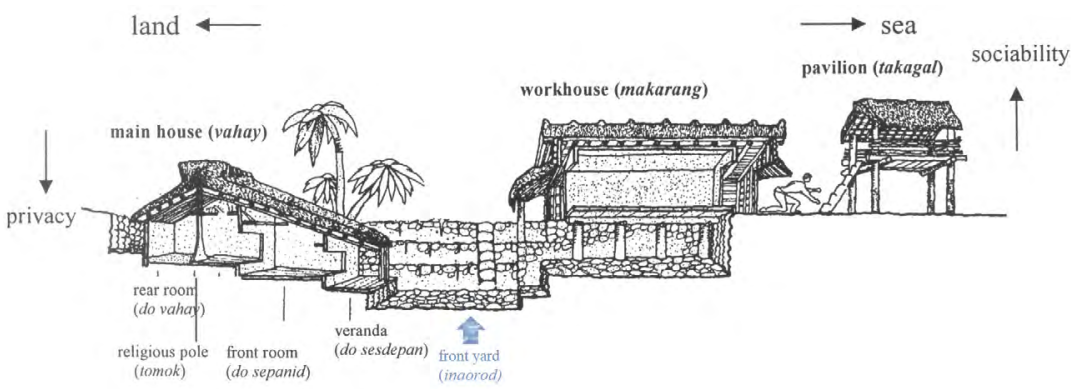

Figure 11.3 The profile of a traditional Yami house compound

Source: Adapted from Huang (1995: Appendix 2). 
The front yard (inaorod), being surrounded by the three main structures, is a space for receiving guests and for outdoor activities, such as scaling fish, displaying flying fish on a rack and hanging up fishing nets. ${ }^{25}$ It is also a ritual space-for example, for welcoming guests to the house inauguration ceremony, for making large canoes, for lifting the large canoes during inauguration ceremonies and for distributing meat and taro during the ceremonies (Kwan 1989: 158; Tsai 1997: 23-24). In fact, Kwan has observed that, within the house compound, the ritual significance of the main house and the front yard was much more salient than for other constructions; while the workhouse and pavilion are used mainly for daily productive and social activities, most rituals are restricted to within the front yard, inside the main house and on the roof of the main house. ${ }^{26}$ The roof of the main house, along with the front yard, can be seen as an interface between the spiritual world and daily life (Kwan 1989). Between the houses, there are some narrow passages, called rarahan nu kuis ('pigs' ways'), ${ }^{27}$ which are usually walled on both sides. When a burial occurs, these passages are the pathways along which the deceased are carried to the graveyard. Traditional houses were situated within compounds, not adjacent to one another, therefore avoiding spirit attacks during burial processions. When a burial occurred, the owners of other houses would fence their compound with bamboo to wall off the spirits of the dead, so the living force of the house would not be endangered (Tsai 1997: 45). During the flying fish ceremony season, if one has caught flying fish, they walk on this passage to avoid passing through those households that have not yet caught their first flying fish. ${ }^{28}$

25 While workhouses and pavilions are also places for socialising and outdoor activities, the front yard is a space 'in-between'. It is a space for socialising and greeting guests before inviting them into the main house. It can be a ritual space during ceremonies and an outdoor space for food processing and preparation. None of the buildings in the house compound has such flexibility. The front yard in Figure 11.3 is below ground level. For some Yami houses, the front yard is at ground level, so visibility is increased.

26 For example, the individual cleansing ritual (after a mourning period and at a certain time during a flying fish ceremony) has to be conducted in the front yard. The offering to the ancestral spirits has to be placed on the sunset side (saray) of the main house's roof. If a man wants to build a small canoe without patterns, he cannot do it in the front yard for such a canoe is not ceremonial and working in the front yard will provoke the spirits' (and villagers') attention (Kwan 1989: 158-59).

27 Sometimes it is also called rarahan nu ku rang ('the path of the spiritual world').

28 It is permissible to pass through households that have already caught and consumed their first catch (usually one fish). I was told the reasons were to avoid showing off and arousing others' jealousy and not infringing on another household's fortune (when those households have not yet caught their first flying fish). 
Between 1966 and 1980, the government dismantled most of the traditional Yami houses and built cement dwellings in a checkerboard pattern for the Yami, to modernise them. Traditional houses were only preserved in two of the six villages on Lanyu. Yami were not accustomed to the confined space in the cement dwellings; they chose instead to stay in the traditional house compounds. ${ }^{29}$ From the mid-1990s, the government subsidised renovation projects. Yami cement houses have begun to grow in size. ${ }^{30}$

In the village where I was doing fieldwork, the traditional house area was fortunately preserved, with the newly built cement dwelling built adjacent to it (see Map 11.1). From Map 11.1, we can see that, in the traditional living area, the size of each house compound varies and the passages between them are meandering. In the cement house dwelling area, the passages are straight because of the checkerboard design.

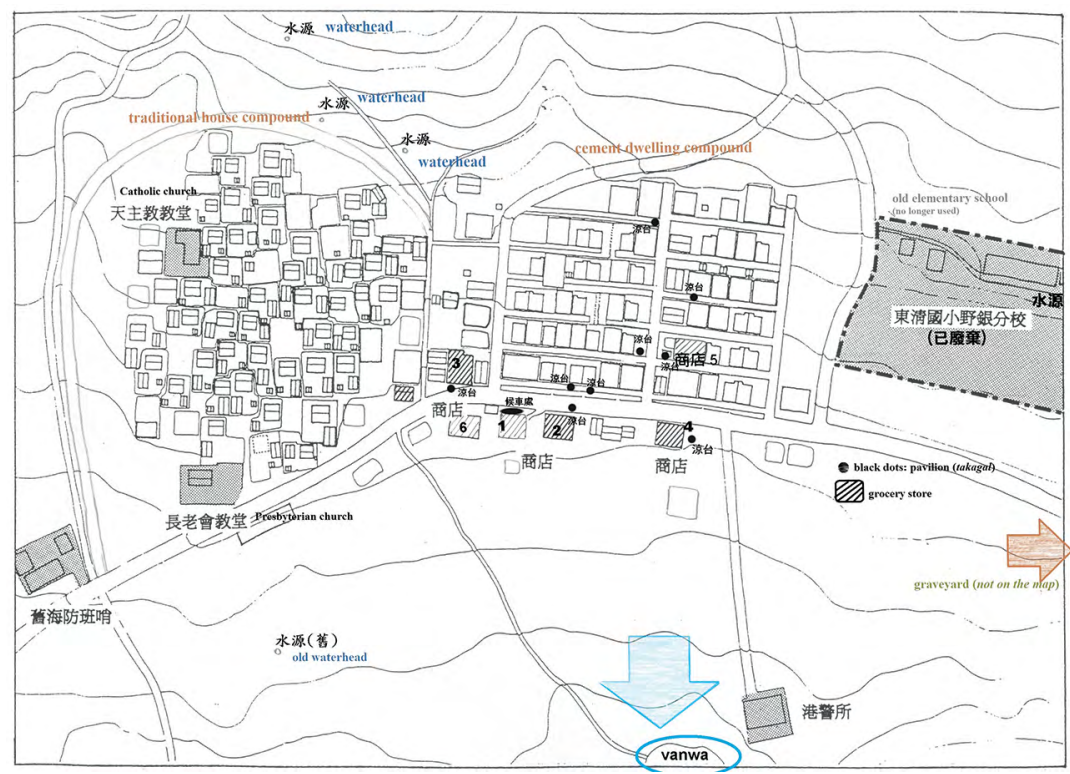

Map 11.1 Map of Ivalinu village

Source: National Taiwan University Building \& Planning Foundation (1999: 32).

29 For the two villages where the old houses were saved, the villagers had the luxury to choose. For those villages where the traditional houses were gone, villagers slept on the roof or altered the building, adding some wooden structures.

30 The base of the cement dwelling (built between 1966 and 1980) is 39.6 square metres. The renovated house was built on the original foundation. In 1997, the foundation was expanded to 165-98 square metres (Chang 1998: 84), which was 4.1 to 5 times the original. 
In contrast to the traditional houses, the cement dwellings do not have a front yard (inaorod). The space in front of the house doors has become an in-between liminal space-belonging to the household but also constituting social public space, akin to the front yard. In the daytime, women often make bead necklaces or other similar handicrafts in front of the house. In the afternoon and evening, Yami sit on plastic chairs in this space, chatting with one another and enjoying snacks and drinks. Nevertheless, in the cement house area, the house space is slowly expanding and the front yards often merge with the village passages. The roofs of the cement houses were almost touching one another. Sometimes the space between one house and the next was too narrow to smooth the cement on the walls of the houses. Some people have their takagal ('pavilion'), or even the whole second floor, built on top of the passages, rendering the passages corridors with overhangs. Thus, the irregular and crooked pattern of passages of traditional living extends to the cement house area; even though the lanes between rows were designed to be straight, since the houses are expanding, the lanes are shrinking, and people's movements zigzag accordingly.

The growing size of cement houses certainly embodies a Yami idea: the development cycle of a house parallels the life cycle of a couple (see Chen 1995). Similarly, the passages within the cement house area have become crooked; however, they are usually not blocked. Except for some rare cases, there is always a narrow lane: the 'pigs' way'. ${ }^{31}$

\section{Growing cement houses, rugged passages}

In 2004-05, when I was doing field research on Lanyu (Orchid Island), the cement houses were expanding in size in every village on the island. Old cement dwellings had certain spatial restrictions designed by the government (no larger than 39.6 square metres). The new cement houses far exceeded the original house area. ${ }^{32}$ The observations of a resident Han Chinese, who worked with a nongovernmental organisation and lived in another village, describe this tendency across the whole island at that time:

31 In the rare cases of 'blocking the passage', when houses on the margin of a row use the passages for their own purposes, those passages are less traversed. Thus, the passages might be blocked at the end. But most of the passages in the cement house area are not obstructed.

32 Lin's research showed that the house unit area was expanding and therefore the village paths were narrowing. She investigated 13 renovated house plans in Iraralay village and found that the average area tripled, becoming 3.09 times the minimum. The paths in Iraralay's cement house compounds were formerly 8 metres wide but have now narrowed to between 2.9 and 4.7 metres. The north-south pathway was 5 to 10 metres and now is 4.7 metres (Lin 2004: 3). 
Concerning fire safety, we have had no fire accident here on the island. Once it happens, you see, there is no fire lane between house and house; how can a fire truck come through? It is not only about the fire safety but also concerns landownership. There was no regulation about building coverage ratio and space. Now the houses are expanding and there are no fire lanes.

In the village where I stayed, one renovated cement house had its second floor over the passage and a staircase to the second floor had been built across the path. Therefore, the front yard had been merged with the passage and become part of the house. Sometimes, the house owner would hang up clothes and blankets on a rack over the passage and passers-by would have to make a detour. They would walk on a narrower lane outside the house area. For the villagers, this might be inconvenient, but it was still acceptable for the owner to maintain a lane-the pigs' way (rarahan no kuis) —outside the house area.

Traditional Yami main houses face the sea. The main entrances of the cement dwellings also face the sea, and a large number of households have their own ladder at the backdoor. A house owner once pointed to his ladder and explained to me:

My ladder was made of wood. Why not use cement? [Because, if] there is a burial and people need to carry the deceased to the graveyard, I can take my ladder in [to the house]. This passage is a public passage. They [those who had cement staircases] are breaking the rule. You see, there is no path if we walk up to here [pointing to the aisle behind his backdoor]. (Syaman L., male, aged in his fifties)

What did he mean by 'there is no path'? It derives from the idea that the 'front yard is part of the house', which we have seen in Figures 11.2 and 11.3. During construction and the process of grouting the cement houses, the house can be expanded to such a degree that there is no room for passages, and the front yard and the passage become almost inseparable.

Enlarging the house space requires marking a new boundary for the house. The enclosure and walling off of the household in a cement house area is more prevalent than in the traditional house area. Several houses have cemented their backdoor ladders at the edge of the passage- a phenomenon described as 'breaking the rules', proving that not everyone obeys the consensus about keeping a passage open for pedestrians. However, the narrow pigs' way is saved, although it might be 
pushed aside. The expansion of individual house space usually results in the shrinking of public space, although the regulations, especially those regarding spiritual beliefs (for carrying a dead body or ceremonial flying fish), still limit individuals' improvisation.

We have seen the expansion of front yards in the cement house area. The front yard is part of the traditional Yami house compound, a place for daily work and socialising, but also a ritual space for welcoming guests in the house inauguration ceremony, lifting large canoes and distributing meat and taro in the canoe inauguration ceremony. In the past, there was no static 'public space' within a Yami village. ${ }^{33}$ When there was an inauguration ritual, people gathered at the host's house, being received first in the front yard. The front yard is a space that can be ritual and social, semi-public or totally private. The only places that could always be counted as 'public' were the passages, the 'pigs' ways', which do not belong to any household; everyone is free to walk on them. Those passages run between house compounds and should not be blocked. Today, the checkerboard design of the cement house area does not include a front yard, so people have expanded the space in front of the house, merging it with the passage and therefore infringing on the 'public' space. People have to make detours when they find the front yards are encroaching on these passages. This, however, is not exceptional, since the Yami are always making detours in their daily lives. For example, when they are carrying a heavy load of root crops or bringing flying fish from the sea, they tactically manoeuvre to avoid stepping into another's house area (including the front yard). If they are carrying leftovers to feed the pigs, they also avoid passing through others' front yards.

33 Within the village housing area, there were no officially demarcated 'public places' in which the community could gather. When an inauguration ritual takes place, the host's front yard becomes a semi-public place. Thus, 'public space' is fluid in a Yami village (also see Huang 1995: 78-79). In contrast, there are a few public spaces in the Yami world but they are outside the village housing area-for example, vanwa (vanoa: 'landing place', 'beach', 'small bay', 'harbour') (Rau and Dong 2006: 554)—where men gather for seasonal rituals (in the flying fish season and to worship [mipazos]) and for canoe launching ceremonies. The other public space is the graveyard, which everyone avoids. Women look for seaweed/shellfish along the beach (keysakan: 'seashore', 'reef', 'intertidal zone'), which might be classified as public, but keysakan is not as ceremonial as vanwa. 


\section{Discussion and comparison}

In this section, I discuss the differences between Yap and Yami 'path(s)': 1) the vocabularies about 'path(s)' and their relations with compliance/ improvisation; 2) paths as a landscape, and a relevant idea about the publicness of the village path(s); and 3) 'pathing' as movement and its associated etiquette.

First, Yapese have a rich vocabulary describing 'path(s)' and connections, such as the path (kanaawoq), political connections (thaaq) and political alliances (nug: 'nets'; and ban: 'side'), to name just a few. These words are endowed with profound meaning and implications, suggesting how one should behave along those connections. In contrast, Yami do not have a rich vocabulary for 'path(s)'. In the Yami language, the most common word for path(s) is rarahan, which is derived from rahan ('footprints') and refers to paths, roads and trails on which people walk. ${ }^{34}$

The fact that rarahan stems from rahan ('footprints') suggests human actions have created paths for descendants to follow. In fact, village life is full of innovations and accompanying criticisms. ${ }^{35}$ The Yami are typical bricoleurs in building their own cement houses, repairing scooters and doing various handyman tasks such as plumbing or electrical work-tasks that were previously unfamiliar to them. They are cautious about violating taboos and dread their consequences; therefore sometimes they appear conservative. Nevertheless, the range of trials and errors in Yami daily life is far greater than for the Yapese. As Chen (1996) has observed, the Yami are not hesitant about embracing new materials to reach particular ends (such as adopting aluminium or plastic food containers or using asphalt or tin for roofing traditional houses). As long as these alternatives have safely undergone an initial trial period, others will emulate the innovators (Miller 1982; Chen 1996). In contrast, in Yapese daily life, the emphasis is more on being attentive to others' needs and accommodating the commands from those of higher rank. Yapese highly value demonstrating one's mindfulness and vigilance in behaviour and showing one's respect

34 Other words, such as nanad ('round-island highway') or onong ('walk past', 'forever', 'decide by oneself'), are not as salient as rarahan.

35 In this regard, Kao and I have different opinions about improvisation in Yami society. Kao considers Yami are more cautious in innovating and prefer following their predecessors' footprints. For example, the elderly would not try an unfamiliar cooked fish and a new architectural design might arouse the community's gossip (Kao 2014). By contrast, I consider Yami social life to be full of improvisations/ innovations as long as they do not break taboos; taboos delimit the range of innovations. 
to the established order (thaaq). Improvisations do often occur (Throop 2010: 31-32), but cultural value is placed on deliberation: community goals and needs have to be taken into consideration before one takes action. Compared with Yami, who emphasise that 'men create paths', Yapese take longer to evaluate the possible consequences of any innovations.

There is also a sharp contrast between Yap and Yami when it comes to village paths as a physical landscape and their publicness. Village paths in Yap are flat, wide and kept tidy, while Yami village rarahan around traditional house compounds are zigzagging and curved. For Yapese, village paths and the meeting house (pebay) beside them are public spaces. Every household has an obligation to weed and maintain the village paths. When outsiders drive cars on village paths or near the meeting house, they must slow to show their respect. If an outsider dares to make noise on the village path, he or she will be severely punished-fined or, sometimes in the past, beaten. For the Yami's traditional dwelling patterns, there was no static or demarcated 'public space' in a village. Any front yard of a house compound could be considered public when the household was holding a ceremony. The only areas that might be classified as strictly public, the village paths or passages, are sandwiched between house compounds (in the traditional house area), even merging with the house front yards (in the cement house area).

Physicality also influences people's pathing. The Yami constantly make detours on their rugged paths, while the Yapese follow the norms of walking manners on their wide, tidy paths. If the Yami were asked, 'How do parents teach their children to walk? Is there any special etiquette to pay attention to?', they would ponder for a while and then respond: 'Not really.' It is not something the Yami elders place particular emphasis on. But they would add that elders (parents) will caution children about avoiding others' house areas. In those cases, people can only walk on the 'public' village passages. Although the Yami do not require specific walking etiquette, they have respect for their fellow villagers. They tactically make detours. For the Yami, loads of labour products, including crops and fish, require zigzag pathing.

I characterise the Yami pathing as 'improvising', partly deriving from their meandering walking routes - constantly making choices and finding detours when there is an obstacle on the path. Yami pathing therefore turns every choice into a new opportunity to form a new trajectory (de Certeau 1984: xix). Improvisation also relates to a Yami ideal: people are born to work (or 'all men are created for labouring'), striving to achieve perfection 
in life - the accumulation of wealth, power and knowledge (Kao 2014) and to embody as many relationships as possible (Huang 2005). When one is on one's life course to perfection, improvisations are tolerated and even encouraged as long as one is not violating taboos and imperilling others' wellbeing. Thus, the tactics of Yami pathing in everyday life (métis: 'ways of operating') (de Certeau 1984: xix) are open to a rapidly changing future while also revolving around the limitations imposed by their spiritual beliefs.

In contrasting Yap and Yami, I am not suggesting that when Yapese walk, they never improvise, but rather, when talking about 'walking', Yapese emphasise a stricter protocol: one has to walk in single file; men should be in front of women; one has to look down and at the road; one has to carry a twig or a long basket to display friendliness. Such a walking protocol is absent in Yami society. When I asked the Yapese how people walk and what the regulations or expectations are, almost everyone-male or female, from the north or the south-gave me similar answers. Those answers showed an emphasis on being mindful and attentive to one's walking $^{36}$ and paying respect to the village, villagers and the land-the sediment of ancestral labour, history and relationships.

By contrasting Yap and Yami, we can consider collectivity and individuality, compliance and improvisation, past-oriented temporality and futureoriented intentionality. The attitudinal difference in compliance and improvisation has brought us to the next comparisons: labour, temporality and how they relate to path/pathing, as well as to life's trajectory and forms of life.

\section{Labour, temporality and forms of life}

At first glance, we might say Yapese value respect and compliance while the Yami admire improvisation. Nevertheless, a deeper investigation would find that both groups value human labour. Yapese value past human labour, which has congealed into the land, whereas the Yami value ongoing human labour, which aligns with the striving for perfection of one's life journey.

36 I vividly remember a retired school principal, a Yapese, who nodded when hearing my question: 'It is something the school should have in the curriculum of culture lessons. We should teach our children how to walk, instead of teaching them a fishing skill, which is no longer used.' 
Yami believe that humans are born to labour (Kao 2014) and one's life goals have to be achieved via relentless investment in labour, marked by a series of productive activities and inauguration ceremonies. Daily work and its products also largely determine one's pathing routes: one has constantly to make detours because of the requirements for carrying one's own harvest or catch or because of other's growing houses. Improvisations are tolerated and even tacitly encouraged when one is on the course of achieving one's goal: to perfect one's life course. The Yapese also value labour-the human labour of previous generations that has transformed the environment and rendered it inhabitable, ordered and hierarchical (Egan 1998: 134-58). The various degrees of past investment in labour and human deeds have defined the present contours of social hierarchy. Thus, the Yapese demonstrate high respect for order-the hierarchical order epitomised in the land.

Land (binaw) in Yap is given a primordial value in every dimension of social interaction, as a repository of Yapese hierarchy (Müller 1942; Schneider 1969; Marksbury 1979; Labby 1976; Egan 1998; Lingenfelter 1975, 1977, 1979; Throop 2010). Land helps to cement 'rank, position, and authority' and the value and power in which successive generations' continuous labour is invested (Throop 2010: 43). It has been emphasised throughout the ethnographic literature that 'land is the chief' and a person is the land's 'vehicle or conduit, its voice' (Labby 1976: 16; Throop 2010: 43). Furthermore, stone constructions on the land, such as stone money (rai) and village pathways (kanaawoq), index particular modalities of being (see Parmentier 1985, 1987; Throop 2010). Kanaawoq, denoting 'path, way, road, method', bears certain semantic meanings akin to the Palauan rael ('path') - a sign type referencing the obligation of repetition. For Yapese, the obligation of repetition or of following entails showing reverence to the land and to those who have lived and worked on the land in the past, as well as those who are currently living and working there.

Why is the land so significant in Yap? As Egan and Throop have pointed out, the rank of land-the relative positions on the tabugull taay ('pure/ impure') distinction-is, in fact, defined by the labour investment in it by past generations (Egan 1998: 134-35; Throop 2010:72). Collective human labour has transformed the low-grade, unclean and underdeveloped land into a high-grade and productive land, governed by yalean ('customs') ${ }^{37}$

37 Yapese often translate yalean as 'customs and traditions'. Yalean $n u$ Wa'ab is understood as the 'Yapese way' or, as Egan (1998: 135) puts it, 'the prescriptions of Yapese culture'. 
that prescribe one's behaviour, roles and obligations in a complex of hierarchical relations (Egan 1998: 135; Throop 2010: 72; Krause 2016: 235-36). This term certainly indicates collectivity and temporality; yalean is viewed as something that precedes one's birth by many generations and therefore implies 'largely unquestioned and relatively fixed' ways of doing, thinking and being-in-the-world (Throop 2010: 83). Yapese highly value demonstrating 'respect' (liyoer) to yalean, to piiluung ('chiefs') and to higher-ranked persons or house estates-all of whom are registered in the land. This respect is directed towards predecessors' labour, which has been vested in the land.

The Yapese respect for village paths and stone paths has to be comprehended along with their reverence for the land since land is the embodiment of labour over time. The Yami's improvisation in pathing also relates to their valuation of labour and work: hard work is not only a virtue, but also a defining element of a person.

For the Yami, an ideal life trajectory comprises a series of activities: getting married, bearing children, changing names (teknonymy), building a three-door main house (vahay), building canoes, having grandchildren and changing names again, rebuilding the main house into one with four doors and hosting public ceremonies. Every significant life event is accompanied by an inauguration ceremony that requires hard work (clearing fields, rearing taro and pigs). Those activities compose a life course and a traditional form of Yami life (for comparison, see Rosaldo 1980), ${ }^{38}$ which could be semantically termed as 'obligations of repetition'. Now, influenced by modern nationalised education and pressed by monetary needs, the Yami have begun to work in Taiwanese cities. It seems there is no longer a clear pattern of life; however, the Yami still highly value labour and hard work, as demonstrated in their expanding houses. We are also reminded of the reason the Yami's daily pathing takes an improvised, zigzagging form: people carrying loads of products of their labour (fish or garden products) avoid passing through others' houses because of respect for others as well as not wanting to arouse others' jealousy or infringe on the fortune of other households. In any case, carrying the products of one's labour matters for one's pathing contour. In the Yami's daily tactical

38 This idea of a 'form of life' comes from Rosaldo (1980). The Ilongot's cultural form or pattern could be formulised as 'a number of persons walking single file along paths that shift in direction', 'at times gathering together and at times dispersing' (Rosaldo 1980: 47, 289). This image could also describe the Ilongot's improvised social order, sense of history, social change and social processes (Rosaldo 1980: 54-59). 
improvisations, they are still following the obligations of repetitiongetting married, bearing children, renovating houses, accumulating relations and, most importantly, working hard — to accomplish the ideal life trajectory.

While the Yami might display a particular form of life-improvising one's path (albeit within the restraints of taboos) in the quest to achieve the ideal personhood throughout one's life journey-do Yapese also have an ideal form of life? I would argue they do. As Ingold (2000: 193) has suggested, the concept of landscape itself emphasises form. The Yapese form of life is epitomised in the landscape of village paths (kanaawoq). For Yapese, a historical stone path has been made by generations of predecessors and is carefully maintained by their descendants. Yapese pay high respect to the stone path, much as they respect land (binaw) the sediment of history and a symbol of relationships. But Yapese focus more on how humans are shaped by paths. Walking on the paths, one has to follow rules, etiquette and expectations. As a Yapese learns to interiorise these rules, he or she gradually incorporates yalean nu Wa'ab and 'becomes Yapese', by experientially embodying the hierarchical order of social relations.

\section{Concluding remarks}

Austronesians have various metaphors for social hierarchy: precedence, origin, plants and pathways. I began with the social metaphor of 'paths' and have contrasted the meaning of village paths in two societies. I contend that paths in hierarchical societies such as the Yap are relatively immobile and fixed and endowed with historical depth and multiple metaphors for marriage pathways (McKinnon 1991, 1995), routes of migration, behavioural rules, protocols and etiquette for bodily movement. By contrast, paths and pathways in egalitarian societies such as the Yami are relatively flexible, easily removed and replaced and differ from generation to generation. Their marriage pathways also show a circular pattern over certain generations (three in Yami). ${ }^{39}$

39 In this chapter, I have not discussed marriage pathways. Among the Yami, an incest taboo exists among first cousins. For second cousins (kaposing), the incest taboo is not so strict. In other words, the third-generation descendants of a couple are marriageable. The third cousin (kaprongan) is the preferred pair. The Yami have a circular marriage preference over three generations, which decreases the possibility of creating hierarchy through marriage pathways (Wei and Liu 1962: Ch.5; McKinnon 1991, 1995). 
I am concerned with the dynamism of 'making paths' and how people should walk on paths, what needs to be noticed and what rules must be obeyed on the path. In Yap, the path is the teacher. Kanaawo materialise existing connections-the thaaq. Those who walk on kanaawoq should be mindful and respectful and accommodate themselves to these social relations, which are endowed with temporal and material depth. A kanaawoq remains relatively unchanged. While one is walking on a kanaawoq, one has to obey a certain behavioural code to show reverence to the village, the land and the people over time. The main village path should be kept clean and unobstructed. Yapese describe the protocol of walking on paths as highly homogeneous - unrelated to the respondents' social ranking or region.

By contrast, the Yami emphasise that paths are made by humans. Landscape physicality can be altered because of human interference (such as the varying size of houses). The individual dynamic of 'pathing' is variable, diverse and improvisational because of different contextual interactions, the purposes of a trip (such as carrying a heavy load of fish or crops or going to feed pigs) and whether ritual matters are involved (such as during a burial or the flying fish ceremony season).

As Mauss (1979) noted several decades ago, bodily techniques—walking, running, dancing, jumping, climbing, descending, swimming — vary from society to society. We have seen the differentiated landscapes of village paths, as well as the divergent attitudes, etiquettes and valuations relating to walking and pathing between the egalitarian Yami and the hierarchical Yap. To simplify: for the Yami, paths are made by humans; improvised pathing takes place on an almost daily basis. For the Yapese, paths shape humans; the village paths and stone paths are carefully maintained and demand people's reverence and behavioural compliance.

Despite the dissimilarities, the attitudinal difference between Yap and Yami reflects an underlying commonality: investment in human labour is highly regarded, despite its disparate manifestations in human constructions (paths in Yap), in products (crops, fish and expanding houses in Yami), in temporalities (past orientation in Yap versus present-future orientation in Yami) and in attitudinal emphasis (compliance and reverence in Yap versus improvisation in Yami). By contrasting the modes of path/pathing, I am not intending to essentialise the two ends of the Austronesian hierarchyequality spectrum. Rather, I wish to open a window through which we 
can see the marvellous cultural differences constantly flourishing while ordered around prominent local categories or idioms such as 'path' in the Austronesian-speaking world.

\section{References}

Ballantyne, Keira Gebbie. 2005. 'Textual structure and discourse prominence in Yapese narrative.' PhD dissertation, Department of Linguistics, University of Hawai' i, Honolulu.

Bashkow, Ira. 1991. 'The dynamics of rapport in a colonial situation: David Schneider's fieldwork on the islands of Yap.' In George W. Stocking, jr, ed., Colonial Situations: Essays on the contextualization of ethnographic knowledge, pp. 170-242. Madison: University of Wisconsin Press.

Blust, Robert. 1988. 'The Austronesian homeland: A linguistic perspective.' Asian Perspectives 26(1): 45-67.

Chang, Hsing-Chieh. 1998. 'Restructuring Tao's house in the power of state.' [In Chinese]. MA thesis, Graduate Institute of Building and Planning, National Taiwan University, Taipei City.

Chen, Yu-Mei. 1995. 'Couple, house, and community: The concept of space among the Yami, Lanyu.' [In Chinese]. In Ying-Kuei Huang, ed., Space, Power and Society, pp. 133-66. Taipei: Institute of Ethnology, Academia Sinica.

Chen, Yu-Mei. 1996. 'Cultural contact and material culture change: An ethnoarchaeological example from the Yami, Orchid Island, Taiwan.' [In Chinese]. Bulletin of the Institute of History and Philology, Academia Sinica 67(2): 415-43.

Chiang, Bien (Daniel). 1986. 'The development, moves and inheritance of Yami residence.' [In Chinese]. Bulletin of the Institute of Ethnology Academia Sinica 58: 83-117.

Chien, Shan-hua. 2011. 'On the music of the large canoe inauguration ceremony (Mapabosbos) in Iraralay.' [In Chinese]. In Hu Sheng-ling, ed., 2011 Conference on Musical Arts and Pedagogy, pp. 23-37. Pingtung, Taiwan: Department of Music, National Pingtung University of Education.

de Certeau, Michel. 1984. The Practice of Everyday Life. Berkeley, CA: University of California Press. 
Dobrin, Lise and Ira Bashkow. 2006. "“Pigs for dance songs": Reo Fortune's empathetic ethnography of the Arapesh roads.' Histories of Anthropology Annual 2(1): 123-54. doi.org/10.1353/haa.0.0015.

Egan, James Arthur. 1998. 'Taro, fish, and funerals: Transformations in the Yapese cultural topography of wealth.' PhD dissertation, Department of Anthropology, University of California, Irvine.

Fang, Keng-Shyurng. 1984. 'House and its original study: The Yami tribe, Taiwan aboriginal.' MA thesis, Department of Architecture, Tamkang University, Taipei City.

Fox, James J. 2006. 'Place and landscape in comparative Austronesian perspective.' In James J. Fox, ed., The Poetic Power of Place: Comparative perspectives on Austronesian ideas of locality, pp. 1-21. Canberra: ANU E Press. doi.org/10.22459/PPP.09.2006.01.

Goody, Jack. 1961. 'The classification of double descent systems.' Current Anthropology (1): 3-25. doi.org/10.1086/200156.

Harrison, Simon. 2004. 'Forgetful and memorious landscapes.' Social Anthropology 12(2): 135-51. doi.org/10.1111/j.1469-8676.2004.tb00096.x.

Hezel, Francis X., SJ. 1983. The First Taint of Civilization: A history of the Caroline and Marshall islands in pre-colonial days, 1521-1885. Honolulu: University of Hawai' i Press.

Huang, Xu. 1995. Yami People's Dwelling Culture and Its Transformation. [In Chinese]. Banciao, Taiwan: Daw Hsiang Publishing.

Huang, Yu-chien. 2005. "Exchange" and "individualism": A case study of Ivalinu, Lan-yu.' [In Chinese]. MA thesis, Department of Anthropology, National Taiwan University, Taipei City.

Ingold Tim. 2000 [1993]. 'The temporality of the landscape.' In Tim Ingold, The Perception of the Environment: Essays on livelihood, dwelling and skill, pp. 189-208. London: Routledge.

Kao, Hsin-chieh. 2014. 'The road to perfection: Personhood and labour in Yami culture.' [In Chinese]. Taiwan Journal of Anthropology 12(2): 1-52.

Krause, Stefan Michael. 2016. 'The production of cultural heritage discourses: Political economy and the intersections of public and private heritage in Yap State, Federated States of Micronesia.' PhD dissertation, Department of Anthropology, University of South Florida, Tampa, FL. 
Kwan, Hwa-san. 1989. 'The physical environment and religious thought among the Yami.' [In Chinese]. Bulletin of the Institute of Ethnology Academia Sinica 67: 143-75.

Labby, David. 1976. The Demystification of Yap: Dialectics of culture on a Micronesian island. Chicago: University of Chicago Press.

Lin, Hsi-Chuan. 2004. 'The conflict and adaptation between the house renovation project and the Yami culture in Lanyu: Case studies of building plans.' [In Chinese]. Paper presented to 2004 Conference of Lanyu Research Group, Institute of Ethnology, Academia Sinica, Nankang, Taipei, 20 December.

Lingenfelter, Sherwood Galen. 1975. Yap: Political leadership and culture change in an island society. Honolulu: University of Hawai i Press.

Lingenfelter, Sherwood Galen. 1977. 'Emic structure and decision-making in Yap.' Ethnology 16(4): 331-52. doi.org/10.2307/3773261.

Lingenfelter, Sherwood Galen. 1979. 'Yap eating class: A study of culture and communitas.' Journal of the Polynesian Society 88: 415-32.

Liu, Pin-Hsiung. 1982. 'Yami text: Boat ceremonial songs.' [In Chinese]. Bulletin of the Institute of Ethnology Academia Sinica (54): 147-96.

Lutz, Catherine A. 1988. Unnatural Emotions: Everyday sentiments on a Micronesian atoll and their challenge to Western theory. Chicago: University of Chicago Press. doi.org/10.7208/chicago/9780226219783.001.0001.

McKinnon, Susan. 1991. From a Shattered Sun: Hierarchy, gender, and alliance in the Tanimbar Islands. Madison: University of Wisconsin Press.

McKinnon, Susan. 1995. 'Houses and hierarchy: The view from a South Moluccan society.' In Janet Carsten and S. Hugh Jones, eds, About the House: Lévi-Strauss and beyond, pp. 170-88. Cambridge: Cambridge University Press. doi.org/10.1017/CBO9780511607653.008.

Marksbury, Richard A. 1979. 'Land tenure and modernization in the Yap islands.' PhD dissertation, Department of Anthropology, Tulane University, New Orleans, LA.

Mauss, Marcel. 1979 [1950]. 'Body techniques.' In Marcel Mauss, Sociology and Psychology: Essays, pp. 95-123. London: Routledge \& Kegan Paul. doi.org/ 10.2307/3032558. 
Miller, Daniel. 1982. 'Structures and strategies: An aspect of the relationship between social hierarchy and cultural change.' In Ian Hodder, ed., Symbolic and Structural Archaeology, pp. 89-98. Cambridge: Cambridge University Press. doi.org/10.1017/CBO9780511558252.010.

Müller, Wilhelm. 1942 [1917]. Yap. Human Relations Area Files, New Haven, CT.

National Taiwan University Building \& Planning Foundation. 1999. Plan for Ivarinu Settlement Improvement: Improving Lanyu environment. Phase V: Detailed planning. [In Chinese]. Commissioned by the Council of Aboriginal Affairs, Taiwan Provincial Government, Nantou.

Parmentier, Richard J. 1984. 'House affiliation systems in Belau.' American Ethnologist 11: 656-76. doi.org/10.1525/ae.1984.11.4.02a00030.

Parmentier, Richard J. 1985. 'Diagrammatic icons and historical processes in Belau.' American Anthropologist 87(4): 840-52. doi.org/10.1525/aa.1985.87.4. 02a00060.

Parmentier, Richard J. 1987. The Sacred Remains: Myth, history, and polity in Belau. Chicago: University of Chicago Press.

Parmentier, Richard J. 2002. 'Money walks, people talk: Systemic and transactional dimensions of Palauan exchange.' L'Homme: 49-79. doi.org/ 10.4000/lhomme.156.

Rau, Victoria and Maa-Neu Dong. 2006. Yami Texts with Reference Grammar and Dictionary. [In Chinese]. Taipei City: Institute of Linguistics, Academia Sinica.

Rau, Victoria, Maa-Neu Dong and Ann Hui-Huan Chang, eds. 2012. Yami (Tao) Dictionary. [In Chinese and English]. Taipei: National Taiwan University Press.

Rosaldo, Renato. 1980. Ilongot Headhunting, 1883-1974: A study in society and history. Stanford, CA: Stanford University Press.

Sahlins, Marshall D. 2011a. 'What kinship is (part one).' Journal of the Royal Anthropological Institute 17(1): 2-19. doi.org/10.1111/j.1467-9655.2010. 01666.x.

Sahlins, Marshall D. 2011b. 'What kinship is (part two).' Journal of the Royal Anthropological Institute 17(2): 227-42. doi.org/10.1111/j.1467-9655.2011. 01677.x.

Schneider, David M. 1962. 'Double descent on Yap.' Journal of the Polynesian Society 71: 1-24. 
Schneider, David M. 1965. 'Some muddles in the models: Or, how the system really works.' In Michael Banton, ed., The Relevance of Models for Social Anthropology, pp. 25-85. London: Tavistock Publications.

Schneider, David M. 1969. 'A re-analysis of the kinship system of Yap in the light of Dumont's statement.' Unpublished paper presented at Kinship and Locality: Wenner-Gren Foundation for Anthropological Research-A Burg Wartenstein Symposium, Burg Wartenstein, Austria, 23 August - 1 September.

Schneider, David M. 1984. A Critique of the Study of Kinship. Ann Arbor: University of Michigan Press.

Throop, C. Jason. 2005. 'Suffering and sentiment: Exploring the vicissitudes of pain and experience in Yap (Waqab), Federated States of Micronesia.' $\mathrm{PhD}$ dissertation, Department of Anthropology, University of California, Los Angeles.

Throop, C. Jason. 2009. "Becoming beautiful in the dance": On the formation of ethical modalities of being in Yap, Federated States of Micronesia.' Oceania 79(2): 179-201. doi.org/10.1002/j.1834-4461.2009.tb00058.x.

Throop, C. Jason. 2010. Suffering and Sentiment: Exploring the vicissitudes of experience and pain in Yap. Berkeley, CA: University of California Press.

Tilley, Christopher. 1994. 'Space, place, landscape and perception: Phenomenological perspectives.' In Christopher Tilley, A Phenomenology of Landscape: Places, paths and monuments, pp. 7-34. Providence, RI: Berg.

Traube, Elizabeth G. 1989. 'Obligations to the source: Complementarity and hierarchy in an eastern Indonesian society.' In David Maybury-Lewis and Uri Almagor, eds, The Attraction of Opposites: Thought and society in a dualistic mode, pp. 321-44. Ann Arbor: University of Michigan Press.

Tryon, Darrell. 1995. 'Proto-Austronesian and the major Austronesian subgroups.' In Peter Bellwood, James J. Fox and Darrell Tryon, eds, The Austronesians: Historical and comparative perspectives, pp. 19-41. Canberra: Department of Anthropology, Research School of Pacific Studies, The Australian National University.

Tsai, Hsiao-Chun. 1997. 'The social production of Tao's house.' [In Chinese]. MA thesis, Graduate Institute of Building and Planning, National Taiwan University, Taipei City.

Urban Planning Studio, Department of Civil Engineering, National Taiwan University. 1984. Commissioned Research Report on the Natural and Human Resources in Lanyu. [In Chinese]. Taipei City: Department of Civil Affairs, Taiwan Province. 
Ushijima, Iwao. 1987. 'Political structure and formation of communication channels on Yap island: A case study of the Fanif District.' Senri Ethnological Studies (21): 177-203.

Wagner, Roy. 1974. 'Are there social groups in the New Guinea Highlands?' In Murray J. Leaf, ed., Frontiers of Anthropology: An introduction to anthropological thinking, pp. 95-122. New York: Van Nostrand.

Wei, Hwei-lin and Pin-hsiung Liu. 1962. Social Structure of the Yami, Botel Tobago. [In Chinese]. Taipei: Institute of Ethnology, Academia Sinica. 
This text is taken from Austronesian Paths and Journeys, edited by James J. Fox, published 2021 by ANU Press, The Australian National University, Canberra, Australia.

doi.org/10.22459/APJ.2021.11 